at removing an equivalent volume of cerebrospinal fluid, plus $1 \mathrm{ml}$, before the injection. This should, of course, obviate that danger.

I wish to thank Dr. B. A. Young, medical superintendent, St. Alfege's Hospital, and Dr. B. Gottlieb, senior resident physician, for permission to publish this case, and the latter also for his help in preparing the paper. St. Alfege's Hospital. E. Marion Metcalfe, M.B., B.Chir., D.R.C.O.G. Greenwich.

Shalom, E. S. (1945), Lancet, $2,36$.

Smith, Honor V., Duthie, E. S., and Cairns, H. (1946). Ibid., 1, 185.

\section{Therapeutic Scurvy}

The following case is of interest in that it shows the importance of viewing the body requirements as a whole when placing any patient on a dietetic regime.

\section{CASE RePORT}

The patient, a married woman aged 42 , with one son aged 16 alive and well, was admitted to hospital complaining of swelling of the left leg for four weeks, with bruising of two weeks' duration. Five weeks before admission she noticed that her teeth were tender and that her gums were swollen and bled easily. Several teeth were extracted without undue haemorrhage. A few days before admission she got a severe pain in the left thigh, with a "cramping" sensation in the calf and the foot. She was sent into hospital as a case of thrombophlebitis.

Vision was blurred, but there was no definite night blindness. On admission she noticed dryness of the skin. There were no pins-andneedles or paraesthesia, no soreness of tongue, and no haematuria. She had had no serious illnesses, but since the age of 8 had been subject to attacks of migraine, which had become more frequent two years ago. She consulted her doctor, who diagnosed nervous dyspepsia and put her on a diet. This consisted of 2 pints (1.14 litres) of milk a day, which was simmered for some while before being consumed. She also had three eggs a week, steamed fish, bread-andbutter, and milk puddings; but she had no vegetables or fruit of any kind. No drugs were taken except stomach powders.

On examination she was seen to be thin and pale, and her lower gums showed purple-red proliferations between the teeth. In the upper jaw, where the teeth had been extracted, there was no abnormality. Examination of the chest and abdomen revealed nothing abnormal. Blood pressure was $120 / 60$. The left leg was markedly swollen, with discoloration of the whole thigh, the appearance being like an extensive bruise. Both legs showed many small petechiae. A blood count showed: haemoglobin, $58 \%$; red cells, 2,800,000; white cells, 6,000; normal differential count. Blood ascorbic acid was $0.1 \mathrm{mg}$. per $100 \mathrm{ml}$. Urinary excretion of ascorbic acid was $2.15 \mathrm{mg}$. in 24 hours.

It was considered that minimal doses of vitamin $\mathrm{C}$ would be of value. She was put on an ascorbic-acid-free diet and given $15 \mathrm{mg}$. of ascorbic acid daily. After three days she noticed improvement in her teeth and the left leg rapidly became more comfortable. Nine days later objective improvement in the leg and gums could be seen. In four weeks there had been no further bleeding, the bruising had gone, and there were only traces of the petechial haemorrhages, but no fresh ones. After approximately three weeks the urinary ascorbic acid excretion was $7.1 \mathrm{mg}$. in 24 hours and the plasma ascorbic acid was $0.25 \mathrm{mg}$. per $100 \mathrm{ml}$. She was given $150 \mathrm{mg}$. of ascorbic acid daily and discharged from hospital, but it was noticed that large doses of vitamin $\mathrm{C}$ did not produce any particular beneficial effect.

The patient has been followed up since discharge. She still complains of being tired, but the haemorrhages have disappeared and apart from fiatulent dyspepsia she has no symptoms.

\section{COMMENT}

This was a case of scurvy due to grossly deficient diet, and it serves to emphasize the importance of giving adequate vitamin $\mathbf{C}$ with many of the diets used for treating dyspepsias. especially if the milk is boiled. The very small amount of ascorbic acid which was required to cure the condition is also noteworthy. The minimum daily requirement of ascorbic acid for an adult is generally accepted as being in the region of $25 \mathrm{mg}$., but this patient was cured by a dose as low as $15 \mathrm{mg}$. daily. The impossibility of diagnosing scurvy from the gums of edentulous people is once again remarked.

I should like to acknowledge the help given me by Dr. J. R. P O'Brien, of the Biochemical Laboratory, Radcliffe Infirmary, Oxford Patrick Mallam, M.D., M.R.C.P.

\section{Facial Seborrhoea in Arteriosclerotic Pseudobulbar Palsy}

Profuse seborrhoea of the face associated with Parkinsonism is so characteristic of encephalitis lethargica that an exception to the rule is not without interest. In the following case the condition was due to arteriosclerotic degeneration of the brain.

\section{CASE Report}

The patient, a man aged 46 , had never had seborrhoea until his present illness. Six months before admission his wife noticed that he seemed dull and sleepy, that he dribbled saliva, and that both hands were "shaky." He became slow in movement, irascible, and difficult to handle. His speech was slurred and his expression fixed.

On examination he looked older than his years, and his typically Parkinsonian face was thickly covered with a glistening film of sebum. The rest of the body was not so affected. He was given to fits of causeless weeping, but pathological laughter was not observed. He was disorientated for time and place, and showed defective memory for recent events. Insight and judgment were faulty, and he displayed a consistent disregard for cleanliness and the conventions. Speech was slow and slurred; it was embarrassed by Cheyne-Stokes respiration. There was no gross defect of sight. The fundi showed marked arteriosclerosis. There was a supranuclear paralysis of conjugate upward movement of the eyes, lateral and downward movements being intact. The tongue was spastic and could barely be protruded. Marked spastic rigidity of both arms and both legs was present. The left arm and leg were weaker than the right, and there was a left extensor plantar response; the right plantar was flexor. There was a coarse tremor of the fingers of both hands, but it was not typically Parkinsonian. Voluntary effort of one limb increased the rigidity of the opposite side of the body; consequently his incapacity was more pronounced when standing or attempting to walk than it was when lying down. He walked with a spastic shuffle and festination. There was no gross sensory loss, but his mental state precluded tests of the finer modalities. Sphincter control was intact.

The left ventricle was much enlarged. Blood pressure was 280/140. The urine contained a trace of albumin and a few hyaline casts. Blood urea was $60 \mathrm{mg}$. per $100 \mathrm{ml}$. The spinal fluid was normal in all respects, and the Wassermann reaction was negative in both fluid and blood.

Eight months after the first appearance of symptoms he had a series of epileptiform convulsions, between which he remained in an attitude of decerebrate rigidity. Twenty-four hours later he died.

The post-mortem report (Dr. J. G. Cummings) on the findings in the brain was as follows: "A recent haemorrhage filled the left hemisphere. Colloidin sections were cut from various parts of the brain and stained with haematoxylin, van Gieson, P.A.H., da Fano, and by the Gross method. Weigert-Pal preparations were also made. There is a widespread vascular abnormality, with marked proliferation of the intima and endarteritis. Atheromatous patches are present. The most marked damage is in the midbrain and pons, where in addition to vascular changes there are small zones of demyelinization in relation to the vessels. The cerebellum shows slight changes of a similar type and also some loss of Purkinje cells. Very few zones of cellular infiltration are to be seen, but in a few cases in the midbrain and pons there is some perivascular lymphocytic infiltration in relation to damaged capillaries. The appearances are those of arteriosclerosis; there is no evidence of encephalitis."

\section{COMMENT}

This case is of interest in two respects. First, it illustrates the sound rule that encephalitis lethargica should not be diagnosed except during an epidemic of that disease : sporadic cases resembling it almost invariably turn out to be some other condition. Secondly, facial seborrhoea has not hitherto been described in pseudobulbar palsy. Its occurrence in this case is perhaps explained by the unusually rapid onset of facial rigidity, which, as in encephalitis lethargica, came on within a few weeks, in contrast to the usual ingravescent onset in arteriopathic Parkinsonism. The seborrhoea is limited to the face, and it is only in the face that rigid muscles, by their insertion into the skin, can impose immobility on the integument in which the sebaceous glands lie. It is suggested that the seborrhoea which occurs as a temporary phenomenon with rapidly developing Parkinsonian rigidity of the face has a mechanical explanation and is not due to a central autonomic disturbance. This view is in harmony with the current belief that the sebaceous glands are not under nervous control.

Frank A. Elliott, M.B., Ch.B., F.R.C.P., Assistant Physician. Charing Cross Hospital : Neurologist, Bolingbroke Hospital. 